\title{
Patients' knowledge of their lithium therapy
}

\author{
J. Anderson and K. Sowerbutts
}

\begin{abstract}
Aims and method Using a semi-structured questionnaire, we surveyed the patients attending an out-patient affective disorders clinic, enquiring about their knowledge of their lithium therapy.

Recults The response rate was $68 \%$. In general, the level of knowledge relating to their own treatment was good. however we were able to identify particular areas of deficiency in their theoretical knowledge. Clinical implications The only factor we could identify which had a significant effect on patients' level of knowledge was having recelved education on lithium in more than one form.

Lithium is a drug which is used extensively in everyday psychiatric practice, not only in the treatment and prophylaxis of recurrent bipolar and unipolar affective disorders but also in the management of schizoaffective disorders and for aggressive behaviour (Ferrier et al, 1995). However, lithium therapy is not without its attendant risks and its short- and long-term side-effects, dangers of toxicity and need for monitoring of plasma concentrations are well-documented (British National Formulary, Number 31, March 1996). Therefore, it is essential that patients are adequately informed about:
\end{abstract}

(a) How to take the preparation.

(b) What side-effects to expect, both in the short- and long-term and signs of possible toxicity.

(c) Why regular blood tests are important.

(d) The potential for interaction with other medicines and with intercurrent illness.

Such patient education is essential, not only to minimise the complications and dangers of therapy but also to improve compliance, which is an important cause of treatment failure, perhaps in as many as $\mathbf{5 0 \%}$ of patients (Lee et al, 1992).

A survey of 50 out-patients (Delany, 1991) found that $30 \%$ of the patients did not know why blood was taken or what side-effects to expect. 94\% were ignorant of possible long-term effects, $74 \%$ had no understanding of toxicity and dangerous practices were common, such as doubling the dose, taking diuretics and ignoring dehydration. Those over 65 years had significantly lower scores. Delany concluded that compliance and safety could well be improved by repeated simple verbal and written information, although the study did not provide any data to support this.

Lee et al (1992) examined the relationship between knowledge and compliance. They found a very limited level of knowledge and concluded that knowledge acquisition alone is insufficient for enhancing compliance. It is more likely that repetitive instruction which is followed by feedback, reinforcement and reassurance improves compliance, and it may be the interpersonal milieu in which patients are given information that truly matters.

Peet \& Harvey (1991) gave a videotape lecture and written handout containing factual information about lithium to 30 attenders at a lithium clinic. They found a substantial and significant increase in patient knowledge and favourable attitudes to lithium. In a second related paper (Harvey \& Peet, 1991a), they also found a demonstrable improvement in compliance. They concluded that "It is clear that patients can fit very well into the routine of a lithium clinic without having any real understanding of their treatment and that lack of knowledge is apparent only when knowledge is formally tested or untoward events occur". However, they did not examine whether it was the written information, the videotape or a combination of the two that was important for the acquisition of knowledge.

The aims of our study were: (a) to investigate how much patients on lithium knew about their treatment; and (b) to identify any factors which appear to influence this knowledge.

\section{The study}

Most patients taking lithium therapy in the East sector of Glasgow attend an affective disorders clinic at a minimum of three-monthly intervals. On their first attendance at the clinic, patients are given two information leaflets (Harvey \& Peet, $1991 b$; Royal College of Psychiatrists, Patient Information Factsheet no. 8, 'Lithium Therapy: What You Should Know', available from the 
College External Affairs Department upon request). This education is reinforced with verbal information and some have also had the opportunity to view the videotape. The clinic is staffed by a consultant psychiatrist, a senior house officer/registrar and a community psychiatric nurse, in addition to reception and secretarial staff.

We surveyed all the attenders at the clinic over a three-month period (14 clinics). Having been unable to obtain a previously used questionnaire of proven validity we designed a questionnaire, based on the information leaflets, which was to be self-administered. Questions took the form of both open questions (relating to knowledge of their own treatment and general knowledge of lithium therapy), which we scored simply as a mark for a correct answer, and a multiple choice section (relating to theoretical knowledge of lithium therapy), which was scored with a negative marking system.

We also designed a medical sheet, which was appended to the front of the case notes, for the doctor to complete. This included a simple linear scale rating mood, routinely used at the clinic, which ranged from -2 (markedly depressed) to +2 (markedly elated).

\section{Findings}

Ninety-nine patients taking lithium attended the clinic during the study period. Seventy-three completed questionnaires, however six of these were invalidated because incomplete personal details meant they could not be matched to the medical sheet for the purposes of marking. Hence, we achieved an overall response rate of 67 out of 99 patients $(67.7 \%)$. Of the 67 questionnaires analysed the male:female ratio was $1: 1.2$ and the mean age was 49.6 (s.d.=12.9) years. Fifty-four $(80.6 \%)$ had a diagnosis of bipolar affective disorder, $6(9 \%)$ had a diagnosis of unipolar disorder and $5(7.5 \%)$ had a diagnosis of schizoaffective disorder. There was no significant difference in gender ratio or age between responders and non-responders. Among the non-responders there were proportionately more patients with a diagnosis of unipolar (depressive) disorder, but this difference did not reach statistical significance at the $1 \%$ level $\left(\chi^{2}=4.2\right.$.
Table 1 Knowledge of own treatment: scores achieved

\begin{tabular}{lll}
\hline Question & $\begin{array}{l}\text { Number } \\
\text { correct } \\
\text { (score=1) }\end{array}$ & $\begin{array}{l}\text { Number } \\
\text { incorrect } \\
\text { (score=0) }\end{array}$ \\
\hline Duration of lithium treatment & 50 & 17 \\
Preparation & 64 & 3 \\
Dose & 43 & 24 \\
Diagnosis & 45 & 22 \\
Other treatment (prescribed & 45 & 22 \\
Or proprietary) & & \\
\hline
\end{tabular}

$P<0.05)$ and they were all rated as euthymic by the psychiatrist on the day they attended the clinic.

The median duration of treatment was eight years (range one to 20 years). The median dose of lithium was $1000 \mathrm{mg}$ (range 400 to $1600 \mathrm{mg}$ ). Sixty-two (95\%) were rated by the doctor whom they saw as euthymic; the remaining $7(7.5 \%)$ were all rated as mildly depressed $(-1)$ on the linear mood scale.

In terms of education, seven patients denied ever having been given any information about lithium. Of the other 60 responders, 16 said that they had seen only written information, 17 said verbal information only, one claimed only to have seen the video and 26 had received information of more than one type (written and verbal). The median time since education was four years (range 1 to 20 years). However, only 41 patients completed this section. Forty-five $(67 \%)$ had received the information at the clinic and 55 (82\%) described the information as 'useful'.

\section{Open questions}

Knowledge of own treatment

In general, the level of knowledge relating to the patient's own treatment was good, with $42(63 \%)$ scoring 4 or 5 and only $6(9 \%)$ scoring 0 or 1 . Median score was 4 (range $0-5$ ). Table 1 shows the scores achieved for each question. In most cases those scored as incorrect were left blank. rather than answered incorrectly.

We found no significant association between the scores and age, duration of treatment, type of lithium education or length of time since lithium

Table 2 Knowledge of own treatment: number of different types of lithium education

\begin{tabular}{lllll}
\hline $\begin{array}{l}\text { Score (knowledge of own } \\
\text { treatiment: max. 5) }\end{array}$ & No education & $\begin{array}{l}\text { Only I type of } \\
\text { education }\end{array}$ & $\begin{array}{l}>1 \text { type of } \\
\text { education }\end{array}$ & Total \\
\hline $0-3$ & 5 & 17 & 3 & 25 \\
$4-5$ & 2 & 17 & 23 & 42 \\
Total & 7 & 34 & 26 & 67 \\
\hline
\end{tabular}


ORIGINAL PAPERS

Table 3 General knowledge of lithium therapy (open questions)

\begin{tabular}{|c|c|c|c|c|}
\hline Question & Correct & Not answered & Incorrect & Common incorrect answers \\
\hline Reason for treatment & $39(58 \%)$ & $16(24 \%)$ & $12(18 \%)$ & $\begin{array}{l}\text { Balances the chemicals ... thins } \\
\text { the blood ... controls the } \\
\text { balance of blood cells in the } \\
\text { mind }\end{array}$ \\
\hline Side-effects & $37(55 \%)$ & $26(39 \%)$ & $4(6 \%)$ & $\begin{array}{l}\text { Headache ... agltation . . . } \\
\text { incontinence }\end{array}$ \\
\hline $\begin{array}{l}\text { Long-term side-effects } \\
\text { of lithium therapy }\end{array}$ & $10(15 \%)$ & $53(79 \%)$ & $4(6 \%)$ & $\begin{array}{l}\text { Should not be taken longer than } \\
\text { five years ... build-up in the } \\
\text { liver ... diabetes ... heart } \\
\text { problems }\end{array}$ \\
\hline $\begin{array}{l}\text { Potential drug interactions } \\
\text { Is lithium safe in pregnancy? } \\
\text { (females only analysed) }\end{array}$ & $\begin{array}{l}8(12 \%) \\
20(56 \%)\end{array}$ & $\begin{array}{l}57(85 \%) \\
15(42 \%)\end{array}$ & $\begin{array}{l}2(3 \%) \\
1(3 \%)\end{array}$ & Iron \\
\hline
\end{tabular}

education. However, we did find a positive association between the score achieved and the number of different types of education about lithium that the patient had received (Table 2: $\chi^{2}=13.207,2$ d.f., $P<0.01$ ).

General knowledge of lithium therapy

The results are shown in Table 3. Although knowledge of potential drug interactions was generally poor, 41 responders $(61 \%)$ said that they would consult a doctor before starting any new medication. However, only $9(25 \%)$ of females said that they would consult a doctor if planning a pregnancy, five said that they would stop lithium immediately and one said that they would simply continue taking the lithium. Twenty-one $(58 \%)$ left this question blank.

Table 4 Theoretical knowledge (multiple choice questions): scores obtained for individual questions

\begin{tabular}{|c|c|c|c|}
\hline Question & $\begin{array}{l}\text { Number } \\
\text { correct }\end{array}$ & $\begin{array}{l}\text { Number } \\
\text { incorrect }\end{array}$ & $\begin{array}{l}\text { Number not } \\
\text { onswered }\end{array}$ \\
\hline Blood tests & 141 & 37 & 147 \\
\hline Side-effects & 137 & 55 & 133 \\
\hline $\begin{array}{l}\text { Response to } \\
\text { diarmoea/ } \\
\text { vomiting }\end{array}$ & 123 & 67 & 135 \\
\hline $\begin{array}{l}\text { Response to } \\
\text { symptoms of } \\
\text { toxicity }\end{array}$ & 119 & 39 & 167 \\
\hline $\begin{array}{l}\text { Precautions in a } \\
\text { hot climate }\end{array}$ & 163 & 37 & 125 \\
\hline $\begin{array}{l}\text { Cautions } \\
\text { Total }\end{array}$ & $\begin{array}{r}97 \\
780\end{array}$ & $\begin{array}{r}52 \\
287\end{array}$ & $\begin{array}{l}176 \\
883\end{array}$ \\
\hline
\end{tabular}

The question relating to side-effects had 11 stems, all the other multiple choice questions had five stems so. for the purposes of analysis, scores achieved on this question were reduced proportionately.

\section{Multiple choice section}

Table 4 shows the distribution of scores for each individual question on the multiple choice section. The negative marking system gave a possible range of scores of -30 to +30 . Sixty-five scores were included in the analysis, the other two questionnaires being considered void. The median score was 6.5 with a range of -2 to 26 and an interquartile range of 3.5 to 9.3. We found no significant association between an individual's score and age, duration of treatment, length of time since education or type of education.

However, there were significant associations between MCQ score and the number of different types of lithium education (Table 5: $\chi^{2}=13.963$,

Table 5 Multiple choice questionnaire (MCQ) scores: number of sources of lithium education

\begin{tabular}{llrrr}
\hline & \multicolumn{4}{c}{ Number of sources of education } \\
\cline { 2 - 5 } MCQ score & 0 & 1 & 2 & Total \\
\hline-5 to 4 & 6 & 13 & 5 & 24 \\
5 to 14 & 0 & 17 & 17 & 34 \\
$>14$ & 0 & 3 & 4 & 7 \\
Total & 6 & 33 & 26 & 65 \\
\hline
\end{tabular}

Table 6 Multiple choice questionnaire (MCQ) score: knowledge of own treatment

\begin{tabular}{llcl}
\hline & \multicolumn{3}{l}{ Score on knowledge of own treatment } \\
\cline { 2 - 4 } MCQ score & $\mathbf{0 - 3}$ & $\mathbf{4}$ or $\mathbf{5}$ & Total \\
\hline-5 to 4 & 15 & 9 & 24 \\
5 to 14 & 9 & 25 & 34 \\
>14 & 0 & 7 & 7 \\
Total & 24 & 41 & 65 \\
\hline
\end{tabular}


4 d.f., $P<0.001$ ) and with the score achieved on knowledge of their own treatment (Table 6: $\chi^{2}=12.434,2$ d.f., $P<0.001$ ).

\section{Comment}

Among the responders in our study, knowledge of their own treatment $(63 \%$ achieved a score of $80 \%$ or more) was better than their theoretical knowledge of lithium therapy (only $11 \%$ achieved a score of $50 \%$ or more). Particular areas of deficiency in their theoretical knowledge concerned longer-term side-effects, potential drug interactions, response to diarrhoea/vomiting or to symptoms of toxicity and cautions (saunas, salt in diet, etc.). More questions were left blank (both open and multiple choice) than answered incorrectly, suggesting a lack of knowledge rather than widespread misconceptions. We were particularly concerned with the finding that only $61 \%$ of responders said they would consult a doctor before starting any new medication and that there was generally poor knowledge of the issues relating to lithium in pregnancy.

The level of knowledge was not significantly influenced by age, duration of treatment, type of lithium education or length of time since lithium education. The only significant effect on levels of knowledge which we were able to demonstrate was having received more than one form of lithium education (most commonly written and verbal). Therefore, it appears that, in this patient group, reinforcement of information can improve knowledge. We have communicated these findings and made some suggestions to those presently responsible for this clinic.

There are a number of shortcomings to our study. Patients were not randomly selected which may have led to an over-representation of patients responding positively to testing and education. In addition, some subjects had apparently, by their own report, received more forms of education than others. Hence our findings would also be explained if those patients more able to benefit from education were those who requested more information from staff or made themselves more available to this end by attending the clinic more regularly. In addition, the questionnaire is of unknown validity, but is closely based on information which the majority of those tested had previously had access to and hence, we consider, was a reasonable measure of the effectiveness of the educational techniques in use at the time. Notwithstanding these limitations we consider that our study has merit in that we have identified areas of deficiency in this patient group's knowledge of lithium which are now being addressed locally, as well as the more general finding that repeated reinforcement of information is the principal factor affecting knowledge acquisition.

\section{Acknowledgements}

Dr G. T. Crocket, Consultant Psychiatrist (retired), formerly of Parkhead Hospital, 81 Salamanca Street, Glasgow G31 5AS; and reception and secretarial staff at Carswell House outpatient clinic.

\section{References}

DELANY, N. (1991) How much do patients on lithium know about their medication? Psychiatric Bulletin, 16, 136137.

FERRIER, I. N., TYRER, S. P. \& BELL, A. J. (1995) Lithium therapy. Advances in Psychiatric Treatment, 1. 102110.

HARVEY, N. S. \& PEET, M. (1991a) Lithium maintenance: 2. Effects of personality and attitude on health information acquisition and compliance. British Journal of Psychiatry. 158, 200-204.

- \& - (1991b) Lithium: Advice for Patients. Sheffield: University of Sheffield.

LEE, S., WING, Y. K. \& WONG, K. C. (1992) Knowledge and compliance towards lithium therapy among Chinese psychiatric patients in Hong Kong. Australian and New Zealand Journal of Psychiatry, 26, 444-448.

PEET, M. \& HARVEY, N. S. (1991) Lithium maintenance: 1. A standard education programme for patients. British Journal of Psychiatry. 168, 197-200.

Jacqueline Anderson, Senior Registrar, Goldenhill Resource Centre, Glasgow; and *Kathryn Sowerbutts, Senior Registrar, Department of Psychiatry, Southern General Hospital, Govan Road, Glasgow

*Correspondence 